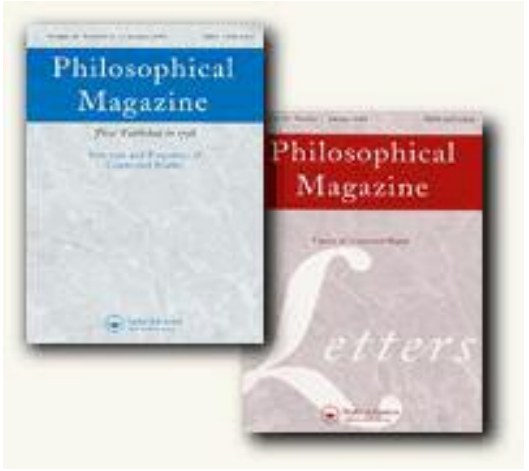

\title{
A transmission electron microscopy and X-Ray diffraction study of microstructural evolution in magnetoresistive $\mathrm{Cu}-\mathrm{Fe}-\mathrm{Ni}$ ribbons
}

\begin{tabular}{|r|l|}
\hline Journal: & Philosophical Magazine \& Philosophical Magazine Letters \\
\hline Manuscript ID: & TPHM-07-Apr-0109.R2 \\
\hline Journal Selection: & Philosophical Magazine \\
\hline Author: & 12 -Mar-2008 \\
\hline Complete List of Authors: & $\begin{array}{l}\text { CAZOTTES, Sophie; Groupe de Physique des Matériaux, UMR CNRS } \\
\text { 6634 université de Rouen } \\
\text { WANG, Guillaume; Institut de Chimie et des Matériaux Paris ESt } \\
\text { UMR CNRS 7182 } \\
\text { FNIDIKI, Abdeslem; Groupe de Physique des Matériaux, UMR CNRS } \\
\text { 6634 université de Rouen } \\
\text { LEMARCHAND, Dany; Groupe de Physique des Matériaux, UMR } \\
\text { CNRS 6634 université de Rouen } \\
\text { RENAULT, Pierre Olivier; Laboratoire de Métallurgie Physique, UMR } \\
\text { 6630 CNRS-Université de Poitiers } \\
\text { DANOIX, Frédéric; Groupe de Physique des Matériaux, UMR CNRS } \\
\text { 6634 université de Rouen }\end{array}$ \\
\hline Keywords: & EFTEM, GMR, granular metals, X-ray diffraction \\
\hline Keywords (user supplied): & Cu-Fe-Ni system \\
\hline \hline
\end{tabular}

\section{S) ScholaroNE \\ Manuscript Central}




\title{
A transmission electron microscopy and X-Ray diffraction study of microstructural evolution in magnetoresistive $\mathrm{Cu}-\mathrm{Fe}-\mathrm{Ni}$ ribbons
}

\author{
S. CAZOTTES ${ }^{\mathrm{a}^{*}}$, G. Y. WANG ${ }^{\mathrm{b}}$, A. FNIDIKI ${ }^{\mathrm{a}}$, D. LEMARCHAND ${ }^{\mathrm{a}}$, P.O. RENAULT ${ }^{\mathrm{c}}$, F. $^{-}$ \\ DANOIX $^{\mathrm{a}}$ \\ a. Groupe de Physique des Matériaux, UMR CNRS 6634, Site Universitaire du Madrillet, BP12, \\ 76801 Saint Etienne du Rouvray cedex, France. \\ b. Institut de Chimie et des Matériaux Paris Est (ex CECM), UMR 7182 CNRS, Université Paris XII, 94320 Thiais, France \\ c. $\quad$ Laboratoire de Métallurgie Physique, UMR 6630 CNRS-Université de Poitiers, SP2MI BP 30172, \\ 86962 Futuroscope Cedex, France
}

\begin{abstract}
The evolution of the microstructure of a granular $\mathrm{Cu}_{80} \mathrm{Fe}_{10} \mathrm{Ni}_{10}$ (at\%) melt spun ribbon is studied by means of transmission electron microscopy (TEM), energy filtered transmission electron microscopy (EFTEM) and X-Ray Diffraction. This system is interesting since large giant magnetoresistance (GMR) values have been measured for this composition. We have shown the presence of two face-centered cubic phases, an $(\mathrm{Fe}, \mathrm{Ni})$-rich phase and a $\mathrm{Cu}$-rich phase. The lattice parameters of those two phases are rather close and no diffraction or elastic contrast acts to evidence the two phases in TEM bright field mode. With EFTEM imaging, we have shown the presence of a fine scale $(\mathrm{Fe}, \mathrm{Ni})$-rich precipitation, inside the $\mathrm{Cu}$-rich fcc matrix. The precipitates are $2-4 \mathrm{~nm}$ large in the as-spun state, and $4-6 \mathrm{~nm}$ large after an annealing treatment of 2 hours at $400^{\circ} \mathrm{C}$. The lattice parameter of the $\mathrm{Cu}-$ rich phase in the as-spun sample is $0.3608 \mathrm{~nm}$, and that of the (Fe,Ni)-rich phase is $0.3610 \mathrm{~nm}$. After a 24 hours treatment at $600^{\circ} \mathrm{C}$, the mean diameter of the particle is $20 \mathrm{~nm}$ and the lattice parameter of the $(\mathrm{Fe}, \mathrm{Ni})$-rich phase has decreased to $0.3600 \mathrm{~nm}$ while that of the Cu-rich phase has increased to $0.3613 \mathrm{~nm}$, which is constistent with a segregation of $\mathrm{Fe}$ and $\mathrm{Ni}$ in the precipitates. The composition and volume fraction of the two phases measured for this annealed sample are in good agreement with the Thermocalc ${ }^{\circledR}$ predictions.
\end{abstract}

Keywords: Cu-Fe-Ni system ; EFTEM ; X-ray ; granular solids, GMR.

\section{Introduction}

Granular solids consisting of magnetic fine particles embedded in a non magnetic medium have been intensively studied in the last decade because of their interesting physical properties and their potential technological applications. The aim of this work is to characterize the evolution of the microstructure of a $\mathrm{Cu}_{80} \mathrm{Fe}_{10} \mathrm{Ni}_{10}$ (at\%) ribbon, as-spun and annealed at different temperatures. The results could later be used in other studies to explain the magnetic behavior and GMR properties of these ribbons.

Indeed, relatively high GMR values were measured on CuFeNi ribbons [1,5]. This GMR effect was attributed to the presence of fine scale magnetic precipitates. The Giant Magnetoresistance (GMR) effect in granular alloys is strongly dependant on the microstructural parameters, such as the precipitates size and size distribution, the composition of the matrix and the precipitates, the number density of the precipitates, the distance between each particle and the morphology of the particles. However, the correlation between those parameters and the GMR is not fully understood yet. In order to be able to correlate the GMR properties of an alloy with its microstructure, a fine quantification of its microstructural parameters needs to be done. We present a method for the characterization of the chemical nature, the volume fraction of the precipitates and the structure of the two phases, i.e. the crystallographic structure and the lattice parameter of the matrix and the precipitates.

Indeed, the nature of the precipitation is strongly dependant on the ribbon studied. In [1], the composition of the studied ribbon was $\mathrm{Cu}_{80} \mathrm{Fe}_{10} \mathrm{Ni}_{10}($ at\%) and the nature of the precipitates was deduced from magnetization curves and Mossbäuer spectrum. Those magnetic analysis revealed the presence of fine bcc $\alpha$-Fe precipitates with a radius slightly larger than $1 \mathrm{~nm}$. In [2], some spinodally decomposed (Fe,Ni)-rich precipitates, were observed with High Resolution Transmission Electron Microscopy in a $\mathrm{Cu}_{60} \mathrm{Fe}_{20} \mathrm{Ni}_{20}$ (wt \%) ribbon. In reference [3], X-Ray measurements were performed on $\mathrm{Cu}_{100-\mathrm{x}} \mathrm{Fe}_{20} \mathrm{Ni}_{\mathrm{x}}(\mathrm{x}=0,5,20)$ ribbons which evidenced the presence of $\alpha$ - $\mathrm{Fe}$ for $\mathrm{Cu}_{80} \mathrm{Fe}_{20}$ and $\mathrm{Cu}_{75} \mathrm{Fe}_{20} \mathrm{Ni}_{5}$ ribbons. All those different microstructures can be explained by the fact that the ribbons are in a non equilibrium state and that their microstructures are highly dependent on the elaboration technique and elaboration parameters. Thus, this bibliographical survey indicates that each type of ribbon should be characterized to get microstructural informations .

This paper presents the evolution of the microstructure of a $\mathrm{Cu}_{80} \mathrm{Fe}_{10} \mathrm{Ni}_{10}$ (at\%) ribbon, as-spun and annealed at different temperatures. The microstructure evolution is observed by conventional TEM, Energy Filtered Transmission Electron Microscope (EFTEM), Energy Dispersion X ray spectrometry (EDX) and X Ray Diffraction (XRD). Energy-filtered (EF) imaging in the transmission electron microscope (TEM) is a widely 
used technique for acquiring qualitative data at high spatial resolution [8-10]. This technique provides images with a chemical contrast. The filtered images are element maps.

The aim is to provide structural information for the studies of the magnetic behaviour and GMR properties of those ribbons. The results can be used in order to interpret the magnetization data obtained by [1-5].

\section{Experimental procedure}

Master alloys of $\mathrm{Cu}_{80} \mathrm{Fe}_{10} \mathrm{Ni}_{10}$ (at \%) have been prepared by arc melting of pure elements. Ribbons were obtained by conventional melt spinning and rapid solidification processing in an helium atmosphere using a steel wheel rotating at a surface speed of $\sim 25 \mathrm{~m} / \mathrm{s}$. The ribbons were $5 \mathrm{~mm}$ wide, $60 \mu \mathrm{m}$ thick and several meters long. The ribbon was rapidly solidified, the cooling rate is approximately $10^{5} \mathrm{~K} / \mathrm{s}$, and its microstructure is in a metastable state.

As the main objective of the project is to correlate the magnetic properties of this ribbon with its microstructure, the annealing temperatures were chosen to maximize the giant magnetoresistance ratio. For this system, the best GMR values were observed for specimens annealed for 2 hours at temperatures around $400^{\circ} \mathrm{C}$ [11]. A specimen was thus heat treated $2 \mathrm{~h}$ at $400^{\circ} \mathrm{C}$. Moreover, in order to reach a stable state for this system and assess the Thermocalc ${ }^{\circledR}$ predictions, another specimen was annealed at $600^{\circ} \mathrm{C}$ for $24 \mathrm{~h}$

TEM specimens were milled directly from ribbons in a GATAN PIPS system at low energy ( from 5 to $3 \mathrm{keV}$ Ar) and low incidence (from $\pm 6^{\circ}$ to $\pm 3^{\circ}$ ). The sample was milled on both faces in order to study the center of the ribbon. TEM observations and energy filtered images are obtained/acquired on a TECNAI F20 operating at $200 \mathrm{kV}$. The microscope is equipped with a Field Emission Gun (FEG), a Gatan Imaging Filter (GIF) for EFTEM imaging and a EDAX-EDX spectrometer. The electrons with a specific energy loss range are used to form an image showing chemical contrast. Each specific energy loss range is characteristic of one element. The filtered images are thus element maps. The GIF is also used simply to remove electrons that have suffered an energy loss of more than a few electron volts to produce a so-called zero-loss image [9]. The zero loss image is created with the remaining electrons, it has a better contrast than the bright field images, particularly in the case of thick specimens.

When an element is present in a much higher concentration in the particles than in a matrix, the EFTEM images reveal it as bright features on a darker background.

X Ray Diffraction analyses were performed on a commercial Bruker D5005 diffractometer. Complementary theta/2theta measurements were performed on a high-resolution Seifert MZ VI HR diffractometer with a tworeflection Bartels monochromator. We used the symmetric Ge 220 reflections and a $0.1 \mathrm{~mm}$ slit in the monochromator to obtain the $\mathrm{Cu}-\mathrm{K} \alpha 1$ radiation $(0.15406 \mathrm{~nm})$ of a sealed $\mathrm{X}$-ray tube (linear focus).

\section{Results and discussion}

\section{Thermodynamics}

There is a miscibility gap in the $\mathrm{Fe}-\mathrm{Cu}$ phase diagram which is still present in the ternary system $\mathrm{Cu}-\mathrm{Fe}$ Ni. According to the literature [5-6], and for the studied compositions, the fcc $\gamma$ phase, present at high temperature, decomposes into two fcc phases $\gamma_{1}$ and $\gamma_{2}$. The $\gamma_{1}$ phase is the Cu-rich phase and the $\gamma_{2}$ phase is the (Fe,Ni)-rich phase. A bcc Fe-rich phase can also appear for annealing at temperatures lower than $400^{\circ} \mathrm{C}$. Thus, at $400^{\circ} \mathrm{C}$, Thermocalc $\AA$ predicts the presence of $\gamma_{1}, \gamma_{2}$ and the bcc iron phase, and only $\gamma_{1}$ and $\gamma_{2}$ for an annealing temperature of $600^{\circ} \mathrm{C}$. The Thermocalc $\AA$ calculated composition (at \%) and phase fraction of each phase are presented in table 1 and the corresponding calculated phase equilibria is presented in figure. 1.

'[Insert table 1 about here]'

'[Insert figure 1 about here]'

\section{Transmission Electron Microscopy}

Transmission Electron Microscopy observations of the as-spun sample indicates that the ribbon is composed of $\mathrm{Cu}$-rich fcc grains, see figure 2 . Their size is in the range of $0.5-1 \mu \mathrm{m}$. The diffraction pattern indicates that the structure of these grains is face centered cubic with the same lattice parameter as copper, i.e. a $=0.361 \pm 0.005 \mathrm{~nm}$. No bcc phase was observed on the diffraction pattern. With conventional TEM, it was not possible to identify phase segregation in the ribbons. That means that no diffraction or elastic contrast acts to evidence any second phase in bright field mode. Indeed, as the $\gamma 1$ and $\gamma 2$ phases have the same face centered cubic crystallographic structure and the lattice parameter of fcc $\mathrm{Cu}$ is $0.3610 \mathrm{~nm}$, the one of $\gamma-\mathrm{Fe}$ is $0.3646 \mathrm{~nm}$ 
and the one of fcc $\mathrm{Ni}$ is $0.3524 \mathrm{~nm}$. Thus the unit cell parameters of these two phases are rather close, and it is not possible to evidence their presence with conventional bright-field TEM. EFTEM is an alternative solution to localise the iron and nickel in the ribbon, and thus the formation of $\gamma 2$ in the ribbon.

'[Insert figure 2 about here]'

\subsubsection{As spun sample}

EFTEM indicates the presence of fine scale (Fe,Ni)-rich precipitates. The zero loss image, and the elements maps are presented on figure 3. Some dark regions are present in the zero loss image, with an irregular shape and a size of 10-20 nm. Those particles give no additive signal on the copper, iron and nickel elemental map. It is most likely surface oxides or surface damage due to the PIPS milling. Whereas no precipitation is visible on the zero loss image, the (Fe,Ni)-rich precipitates appear bright in the iron and nickel maps and dark on the copper map, showing that the particles are enriched in iron, and that their copper concentration is lower than the one of the matrix. In the nickel map, the contrast is less clear, indicating that there is still some nickel in the copper matrix. This result is consistent with the complete miscibility of $\mathrm{Ni}$ in $\mathrm{Cu}$. On the contrary, the precipitates are clearly identifiable on the copper and iron maps. The precipitates appear spherical, with a high number density and their size is in the range of 2-4 $\mathrm{nm}$. It was not possible with this microscope to probe a smaller area without avoiding irradiation damages. Due to the small size of the precipitates the EFTEM signal is very weak and the noise/signal ratio is high. Thus the interface between the precipitates and the matrix is not clear and it is difficult to identify the precise size of the precipitates. A more precise quantification of the size distribution and number density of the precipitates can not be calculated from this technique. The composition measurements with EDX is also not possible, because of the scale of the precipitates.

'[Insert figure 3 about here]'

\subsubsection{Sample annealed 2 hours at $400^{\circ} \mathrm{C}$}

After a 2 hour heat treatment at $400^{\circ} \mathrm{C}$, no significant evolution was observed in the microstructure of the ribbon. The grains have a face centered cubic structure, with a size in the range of $0.5-1 \mu \mathrm{m}$. The element maps (see figure 4) show the presence of the fine precipitates with a size of 2-6 nm . The measurements were made on a large area to avoid specimen damages. The increase in size is rather small, and in order to estimate it, a technique with higher spatial resolution should be used, such as Field Ion Microscopy for example.

The copper map is very bright and gives no information about the presence of the precipitates, but the contrasts in the iron and nickel maps are clear which allow us to conclude that those precipitates are enriched in nickel and iron. The precipitates are in the range size of 2-6 $\mathrm{nm}$. In order to avoid irradiation damage, it is not possible to get smaller scale filtered images.

'[Insert figure 4 about here]'

\subsubsection{Sample annealed 24 hours at $600^{\circ} \mathrm{C}$}

After annealing at $600^{\circ} \mathrm{C}$ for $24 \mathrm{~h}$, a drastic change in the precipitate morphology is observed. The precipitates are much bigger and more enriched in iron and nickel than for the as-spun sample whereas the grain size and structure of the matrix are unchanged. The energy filtered images are presented in figure 5, and they show precipitates with a size range of $15-25 \mathrm{~nm}$, with a mean value of $20 \mathrm{~nm}$. By analyzing the iron map, the volume fraction of precipitates is $19 \%$. This calculation was performed using the measured diameter of the precipitates, calculating the total volume of the precipitates and then the volume fraction. The thickness of the specimen is unknown because it is not the same on the border of the hole and $200 \mathrm{~nm}$ away from it. Without the thickness of the sample, this calculation induces an overestimation of the volume fraction of the precipitates. As the particles are bigger than in the as spun state and in the sample annealed at $400^{\circ} \mathrm{C}$ for two hours, it was possible to check the composition of the matrix and particles with an EDX analysis. Several zones were probed , in the center of the precipitates for the $\gamma 2$ phase, and away from the precipitates, i.e. in the matrix, for the $\gamma 1$ phase, and the results are summarized in Table 2. The EDX precision is approximately $1 \%$ and the composition measured for the $\gamma 2$ phase is almost the same as the one predicted by Thermocalc ${ }^{\circ}$. For the $\gamma 1$ phase, there is more iron and nickel in the experimental data than in the Thermocalc $₫$ prediction. The difference is around $2 \%$ for both elements. This difference is maybe due to the fact that neither the precipitates and the matrix are homogeneous in composition in the ribbon. Thermocalc ${ }^{\circledR}$ gives an mean composition value, while only the 
center of the two phases were probed. If the composition near the interface is not the same as in the center of the phases, then the measured value are not exactly the same as the one given by Thermocalc®. Moreover, the volume fraction of the $\gamma 2$ phase is slightly higher than the one given by Thermocalc ${ }^{\circledR}$ which is maybe due to the calculation of this value from the EFTEM images. However, considering the experimental precision of the EDX measurements, the estimation of the size of the particles and the volume fraction of the two phases are in good agreement with the Thermocalc ${ }^{\circledR}$ simulation. After 24 hours annealing at $600^{\circ} \mathrm{C}$, the ribbon has reached a stable thermodynamic state.

\section{'[Insert figure 5 about here]'} '[Insert Table 2 about here]'

\section{$3 \quad \mathrm{X}$ Ray Diffraction}

With the aim of determining the lattice parameter of the two phases and their composition, the samples were studied by X Ray Diffraction (XRD), as shown in Figure 6. In order to avoid as much as possible the overlapping of the Bragg peaks, a first set of XRD measurements were performed at high $2 \theta$ angles (from $86^{\circ}$ up to $148^{\circ}$ ) in a two-circle Bruker D5005 diffractometer working with $\mathrm{CuK} \alpha$ radiations, i.e. using both $\mathrm{K} \alpha_{1}$ and $\mathrm{K} \alpha_{2}$ radiations. From those patterns, a single fcc phase is observed, and no bcc phases are present, in agreement with the diffraction pattern obtained from TEM observations. The precision does not allow confirming the presence of two phases with different lattice parameters. Indeed, all the peaks can be indexed within the fcc structure with a lattice parameter of $0.3607 \mathrm{~nm}$, which is close to the lattice parameter of pure Copper $(\mathrm{a}=$ $0.3610 \mathrm{~nm})$.

\section{'[Insert figure6 about here]'}

In order to analyze the data for the presence of the (Fe,Ni)-rich and $\mathrm{Cu}$-rich phases, a second set of XRD measurements was performed in a 4 circle Seifert 3000 diffractometer in order to increase the precision, i.e. no $\mathrm{k} \alpha 2$ radiation and lower background. Indeed, the incoming monochromatic radiation is $\mathrm{CuK}_{\alpha 1}(\lambda=0.15406 \mathrm{~nm})$ with a Ge (220) 2 reflections Bartels monochromator, and, the diffracted rays are analyzed through a $0.1 \mathrm{~mm}$ slit on a $220 \mathrm{~mm}$ radius circle. The figure 7 presents an example of extraction made on the 331 peaks for the as spun and annealed samples. The peaks are clearly not symmetric and the asymmetry is changing as a function of the annealing temperature. As EFTEM observations showed the presence of two phases, all the peaks were fitted as the sum of two peaks. The diffraction peaks could be well fitted using symmetric Pearson VII function; the background function is a first order polynomial. The area and position of each peak is an indication of respectively the volume fraction and the lattice parameter of each phase. Thus, a least square algorithm is used to perform a least-squares minimization of the objective function, with some constraints on the total area under each peak profile in order to take into account the volume fraction estimated from TEM analysis or Thermocalc $\circledR^{\circ}$.

'[Insert figure7 about here]'

In the case of the sample annealed at $600^{\circ} \mathrm{C}$ for $24 \mathrm{~h}$, the first peak is high, with a small FWHM and the second one is smaller, with a larger FWHM. The FWHM is related with the crystallite size, the microstrain in the sample and the experimental set up [12]. After a 24 hours heat treatment we can expect the micro strain in the ribbon have been released, and the width of the peak is then an indication of the size of the precipitates. Theoretically, the bigger the FWHM is, the smaller the precipitates are. Thus, the major peak is expected to correspond to the $\mathrm{Cu}$-rich phase, while the minor one, with the large FWHM, is expected to correspond to the $(\mathrm{Fe}, \mathrm{Ni})$-rich phase. The same fitting procedure was used for the as spun sample and the sample annealed at $400^{\circ} \mathrm{C}$ for 2 hours. The results are presented in Table 3. The main result of this fitting procedure is the peak position, and then the lattice parameter of each phase.

\section{'[Insert table 3 about here]'}

The lattice parameter evolution is presented in figure 8. In the as-spun state, the lattice parameter for the $\mathrm{Cu}$-rich phase is $0.3609 \mathrm{~nm}$ and the one for the $(\mathrm{Fe}, \mathrm{Ni})$-rich phase is $0.3614 \mathrm{~nm}$. After a 2 hours heat treatment at $400^{\circ} \mathrm{C}$, almost no evolution of the lattice parameter is observed This is in agreement with the EFTEM observations, there was almost no evolution between the as spun state and the sample annealed at $400^{\circ} \mathrm{C}$ for $2 \mathrm{~h}$. A significant evolution is observed after a $600^{\circ} \mathrm{C}$ annealing for $24 \mathrm{~h}$. The symmetry of the peaks has changed, and the lattice parameter of the $\mathrm{Cu}$ rich increases from $0.3609 \mathrm{~nm}$ to $0.3610 \mathrm{~nm}$ while the lattice parameter of the $(\mathrm{Fe}, \mathrm{Ni})$ rich phase decreases from $0.3614 \mathrm{~nm}$ to $0.3600 \mathrm{~nm}$. The theoretical lattice parameter of the copper is $0.3610 \mathrm{~nm}$, the one of the gamma iron is $0.3640 \mathrm{~nm}$, the one of the nickel is $0.3524 \mathrm{~nm}$ and the one of L10 
ordered FeNi is $0.3556 \mathrm{~nm}$ [13]. Assuming the Vegard's law, it is possible to calculate the composition of a solid solution from its lattice parameter. However, this calculation was not possible on this system. Using the experimental composition obtained from the fit for the $(\mathrm{Fe}, \mathrm{Ni})$ rich phase, and the theoretical lattice parameters of $\mathrm{Cu}(0.3610 \mathrm{~nm}), \mathrm{Ni}(0.3519 \mathrm{~nm})$ and $\gamma-\mathrm{Fe}(0.3640 \mathrm{~nm}[14])$, the calculated lattice parameter is $0.3593 \mathrm{~nm}$ instead of 0.3614 obtained from the model. As the $\gamma-\mathrm{Fe}$ phase is not a stable phase, several values are given in the literature for the lattice parameter. In [13], the lattice parameter given for $\gamma-\mathrm{Fe}$ is $0.3454 \mathrm{~nm}$, which gives with the Vegard's law $0.3492 \mathrm{~nm}$ for our composition. The Vegard's law is not applicable in for the sample annealed at $600^{\circ} \mathrm{C}$ for $24 \mathrm{~h}$, it is thus not possible to deduce the evolution of the composition with those measurements. Precise composition measures are in progress with Atom Probe. However, from the evolution of the lattice parameter a qualitative description is possible, the decrease in lattice parameter of the $(\mathrm{Fe}, \mathrm{Ni})$-rich phase after a 24 hours annealing at $600^{\circ} \mathrm{C}$ can be correlated with an enrichment of this phase in iron and nickel while the increase of the $\mathrm{Cu}$-rich phase lattice parameter can be correlated with an enrichment of $\mathrm{Cu} \mathrm{Those}$ results are in agreement with the EFTEM observations. During annealing, there is a segregation of iron and nickel in the $(\mathrm{Fe}, \mathrm{Ni})$-rich precipitates.

'[Insert figure 8 about here]'

Further GMR and magnetic measurements are in progress. The magnetic and GMR properties will be explained using our structural results. It is known that, in order to be fitted, the magnetization data and Mössbauer spectrum need the microstructural parameters such as the size distribution, the chemical nature and the volume fraction of the two phases.

Moreover, some theoretical models (Pogorelov et al, PRB, 58,1998, 425 ; Ferrari et al, PRB , 56, 1997,6086) could fit their magnetoresistance data using some microstructural parameters such as the size distribution, the chemical nature and the concentration of the magnetic particles. Our experimental results could be inserted in those models for the correlation of the magnetoresistance behavior of the CuFeNi system and their microstructural parameters

\title{
Conclusion
}

We have evidenced the presence of (Fe,Ni)-rich precipitation inside a $\mathrm{Cu}$-rich phase in a $\mathrm{Cu}_{80} \mathrm{Fe}_{10} \mathrm{Ni}_{10}$ (at\%) melt spun ribbon. Those two phases have a similar lattice parameter, and no contrast is visible on bright field images. A chemical analysis is necessary to evidence the presence of the precipitates. In the as spun state, the precipitates are 2-4 $\mathrm{nm}$ wide. The lattice parameter of the $\mathrm{Cu}$-rich phase was measured by X-Ray diffraction as $0.3609 \mathrm{~nm}$ and the one of the $(\mathrm{Fe}, \mathrm{Ni})$-rich phase as $0.3614 \mathrm{~nm}$. There is no significant evolution of the microstructure for the sample annealed two hours at $400^{\circ} \mathrm{C}$, whereas the morphology of the precipitates has drastically changed after a 24 hours heat treatment at $600^{\circ} \mathrm{C}$. The precipitates diameter reaches a size of $20 \mathrm{~nm}$ with an experimental composition of $\mathrm{Cu}_{11} \mathrm{Fe}_{53} \mathrm{Ni}_{36}$ in agreement with Thermocalc ${ }^{\circledR}$ predictions. The decrease in the lattice parameter, from $0.3614 \mathrm{~nm}$ to $0.3600 \mathrm{~nm}$, confirms the segregation of the iron and nickel in the (Fe,Ni)-rich precipitates.

Further GMR and magnetic measurements are in progress. The magnetic and GMR properties will be explained using our structural results. Moreover, some theoretical models could fit their magnetic properties and magnetoresistance data using some microstructural parameters such as the size distribution, the chemical nature and the concentration of the magnetic particles. Our experimental results could be inserted in those models for the correlation of the magnetoresistance behavior of the $\mathrm{CuFeNi}$ system and their microstructural parameters.

\author{
Aknowledgements \\ M. Barrico (Dipartimento di Chimica IFM and INFM/INSTM, Università di Torino, Torino Italy) is \\ acknowledged for providing the ribbons.
}

\section{References}

[1] C.S. Martins, H.R. Rechenberg, F. P. Missel, J. Appl. Phys. 837001 (1998)

[2] L.H. Chen, S. Jin, T.H. Tiefel, S.H. Chang, M. Eibschtuz, Phys Rev B 499194 (1994).

[3] M. Barrico, E. Bosco, G. Acconciaioco, P. Rizzi, M. Coisson, Mater. Sci. Eng. A375-A377 1019 (2004)

[4] L.H. Chen, S. Jin, T.H. Tiefel, S.H. Chang, M. Eibschtuz, J. Appl. Phys. 795599 (1996)

[5] S Cazottes, A Fnidiki, D. Lemarchand, F. Danoix, P. Ochin, J.Magn. Magn. Mater. In Press 2007

[6] Y-Y. Chuang, R. Schmid, Y. Austin Chang, Acta Met. 331369 (1985).

[7] C. Servant, B. Sundman,, O. Lyon, Calphad 2579 (2001).

[8] B. Freitag, W. Mader, J. Microsc. 19442 (1999).

[9] P.J. Thomas, P.A. Midgley, Ultramicroscopy 88179 (2001).

[10] S. Lozano-Perez, J. M. Titchmarsh, M. L. Jenkins, Ultramicroscopy 10675 (2006) 
[11] C.S. Martins, F.P. Missell, J. Appl. Phys. 874840 (2000).

[12] R. W. Cheary, A. A. Coelho, J. P. Cline, J. Res. Natl. Inst. Stand. Technol. 1091 (2004)

[13] Y. Mishin, M.J. Mehl, D.A. Papaconstantopoulos, Acta Mat. 534029 (2005)

[14] T. Massalski (Editor), Binary Alloy Phase Diagrams, second edition, (ASM International, 1990)

[15] S.H. Ge, Z.Z. Zhang, Y.Y. Lu, C. X. Li, R. J. Gan, Thin Solid Films 31133 (1997)

\begin{tabular}{|c|c|c|c|c|c|c|c|c|c|c|c|c|c|}
\hline \multirow[t]{2}{*}{ At $\%$} & & \multicolumn{4}{|c|}{$\gamma_{1}(\mathrm{Cu})$-rich phase } & \multicolumn{4}{|c|}{$\gamma_{2}(\mathrm{Fe}, \mathrm{Ni})$-rich phase } & \multicolumn{4}{|c|}{$\alpha$ bcc Iron } \\
\hline & & $\%$ phase & $\mathrm{Cu}$ & $\mathrm{Ni}$ & $\mathrm{Fe}$ & $\%$ phase & $\mathrm{Cu}$ & $\mathrm{Ni}$ & $\mathrm{Fe}$ & $\%$ phase & $\mathrm{Cu}$ & $\mathrm{Ni}$ & $\mathrm{Fe}$ \\
\hline Thermocalc & $400^{\circ} \mathrm{C}$ & 80.94 & 97.48 & 2.50 & 0.02 & 17 & 6.51 & 46.50 & 46.99 & 2.06 & 0.03 & 3.46 & 96.51 \\
\hline predictions & $600^{\circ} \mathrm{C}$ & 82.08 & 95.48 & 4.26 & 0.26 & 17.92 & 9.10 & 36.31 & 54.59 & & & & \\
\hline
\end{tabular}

Table 1: Composition (at \%) and phase fraction (\% phase) calculated from Thermocalc® software for $\mathrm{Cu}_{80} \mathrm{Fe}_{10} \mathrm{Ni}_{10}$ at different annealing temperature

\begin{tabular}{|c|cccc|ccccc|}
\cline { 2 - 9 } \multicolumn{1}{c|}{} & \multicolumn{4}{c|}{$\gamma 1-\mathrm{Cu}$ rich phase } & \multicolumn{4}{c|}{$\gamma 2-(\mathrm{Fe}, \mathrm{Ni})$-rich phase } \\
\cline { 2 - 9 } \multicolumn{1}{c|}{} & $\begin{array}{c}\text { Volume } \\
\text { fraction }\end{array}$ & $\mathrm{Cu}$ & $\mathrm{Ni}$ & $\mathrm{Fe}$ & $\begin{array}{l}\text { Volume } \\
\text { fraction }\end{array}$ & $\mathrm{Cu}$ & $\mathrm{Ni}$ & $\mathrm{Fe}$ \\
\hline $\begin{array}{c}\text { Thermocalc } \mathbb{8} \\
\text { prediction }\end{array}$ & 82.08 & 95.48 & 4.26 & 0.26 & 17.92 & 9.10 & 36.31 & 54.59 \\
$\begin{array}{c}\text { Experimental } \\
\text { measurements }\end{array}$ & 81 & 91 & 7 & 2 & 19 & 11 & 36 & 53 \\
\hline
\end{tabular}

Table 2: Comparison of Thermocalc $₫$ predictions at $600^{\circ} \mathrm{C}$ and experimental measured compositions of the (FeNi)-rich phase and the $\mathrm{Cu}$ rich phase for the sample annealed at $600^{\circ} \mathrm{C}$ for $24 \mathrm{~h}$.

\begin{tabular}{|l|l|l|l|l|l|}
\hline & $\begin{array}{l}\gamma 1-\mathrm{Cu} \text { rich } \\
\text { phase lattice } \\
\text { parameter }(\mathrm{nm})\end{array}$ & FWHM $\gamma 1$ & $\begin{array}{l}\gamma 2-(\mathrm{Fe}, \mathrm{Ni}) \text {-rich } \\
\text { phase lattice } \\
\text { parameter }(\mathrm{nm})\end{array}$ & FWHM $\gamma 2$ & $\begin{array}{l}\mathrm{A} \gamma 1 /(\mathrm{A} \gamma 2+ \\
\mathrm{A} \gamma 1)\end{array}$ \\
\hline As Spun & $0.36096 \pm 310^{-5}$ & $0.65 \pm 0.01$ & $0.3614 \pm 3.10^{-4}$ & $1.2 \pm 0.1$ & 0.06 \\
\hline $\begin{array}{l}\text { Annealed at } \\
400^{\circ} \mathrm{C} \text { for } 2 \mathrm{~h}\end{array}$ & $0.36082 \pm 3.10^{-5}$ & $0.62 \pm 0.01$ & $0.3616 \pm 3.10^{-4}$ & $1.2 \pm 0.1$ & 0.06 \\
\hline $\begin{array}{l}\text { Annealed at } \\
600^{\circ} \mathrm{C} \text { for } 24 \mathrm{~h}\end{array}$ & $0.36103 \pm 3.10^{-5}$ & $0.47 \pm 0.01$ & $0.36038 \pm 6.10^{-5}$ & $1.1 \pm 0.1$ & 0.17 \\
\hline
\end{tabular}

Table 3: Fitting parameters for the X-Ray Diffraction pattern. A $\gamma 1$ is the surface of the peak corresponding to the $\gamma 1$ phase and $A \gamma 2$ is the surface of the peak corresponding to the $\gamma 2$ phase. The ratio $A \gamma 1 /(A \gamma 2+A \gamma 1)$ is an indication of the volume fraction of the FeNi rich phase. 


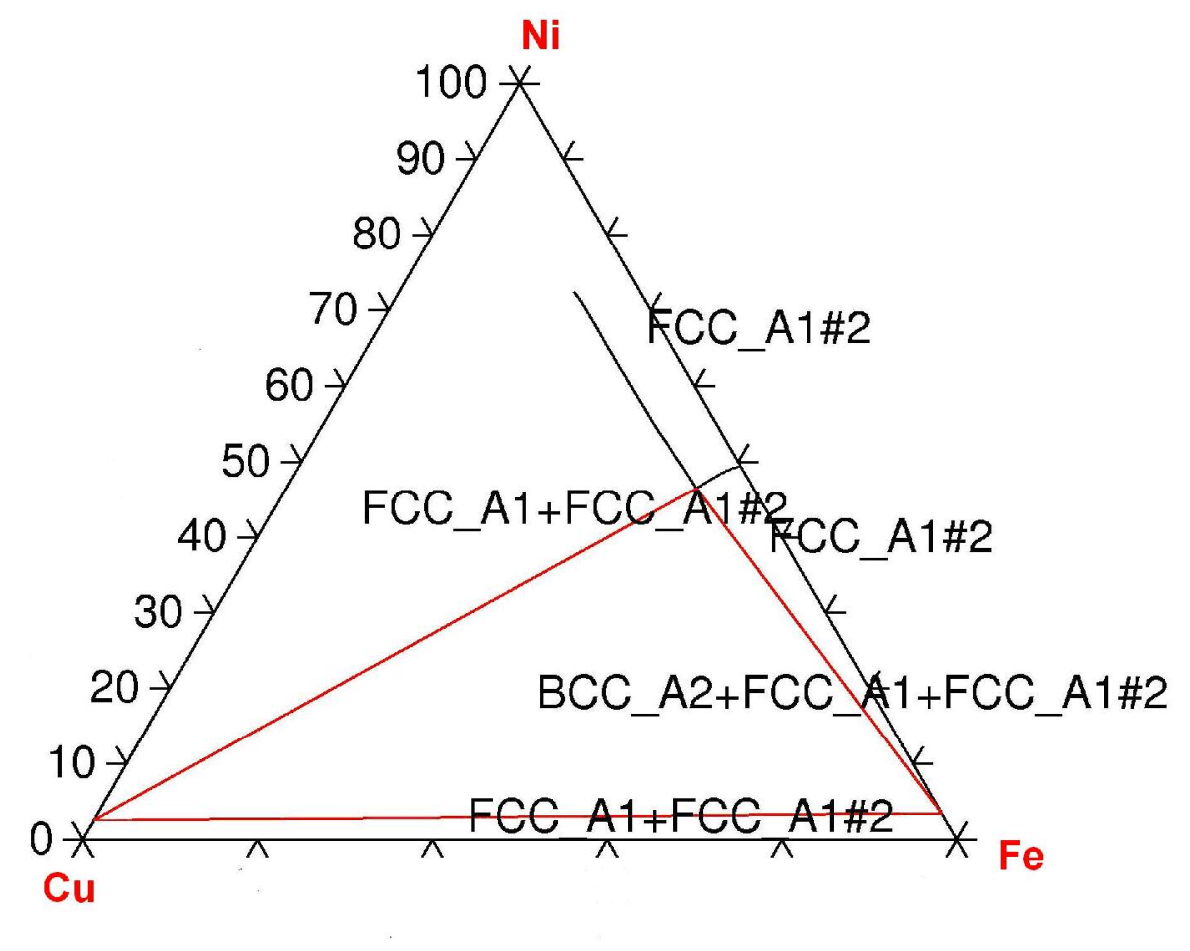

Figure 1: Thermocalc ${ }^{\circledR} \mathrm{CuFeNi}$ equilibrium phase diagram at $400^{\circ} \mathrm{C}$. The $\mathrm{FCC}_{-} \mathrm{A} 1$ is the $\gamma_{1}$ phase, the FCC_A1 $\# 2$ is the $\gamma_{2}$ phase and the $B C C \_2$ is the bcc iron phase
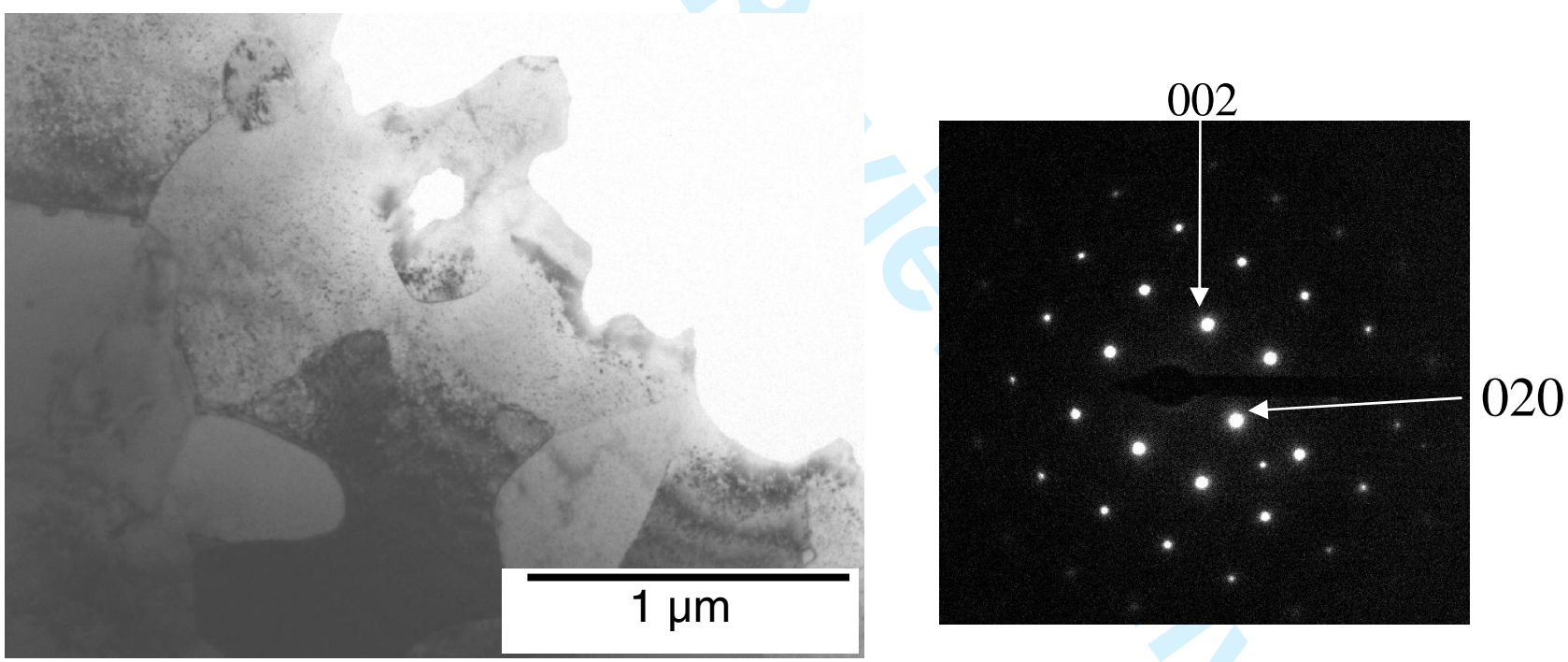

Figure 2: TEM bright field micrograph of the as-spun ribbon and diffraction pattern of a $<100>$ zone axis oriented grain. 


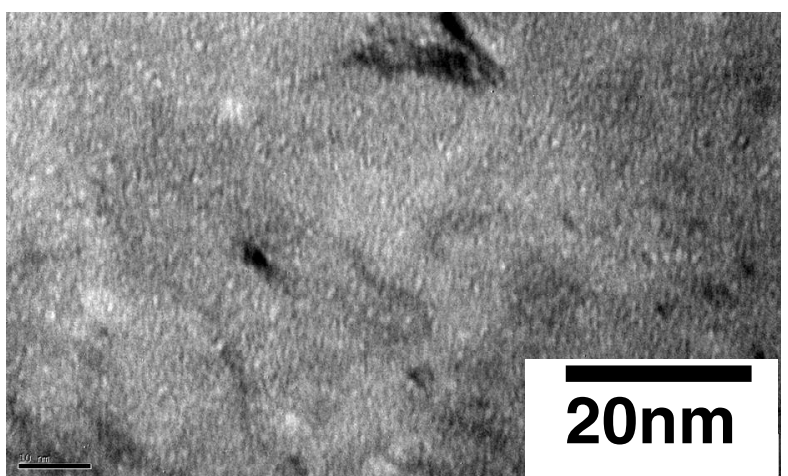

Zero loss image

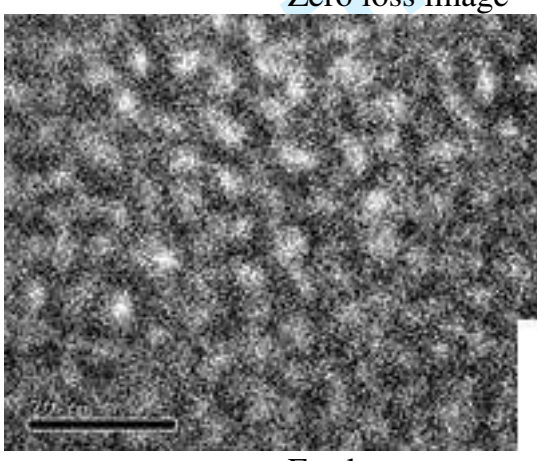

Fe element map

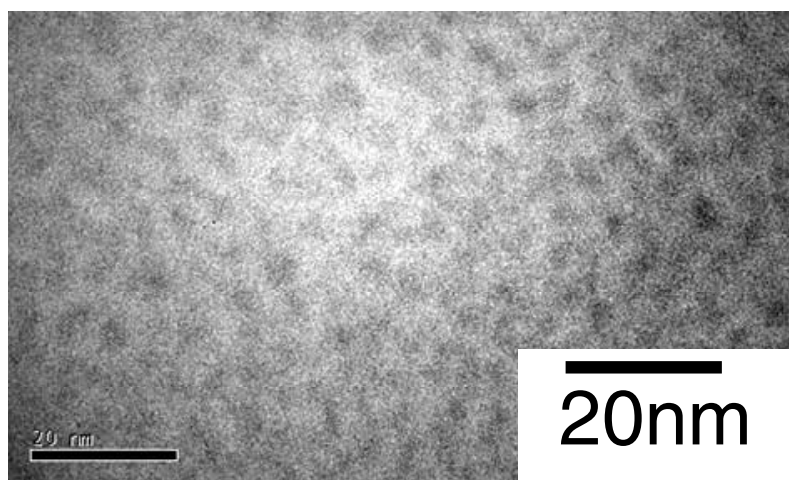

$\mathrm{Cu}$ element map

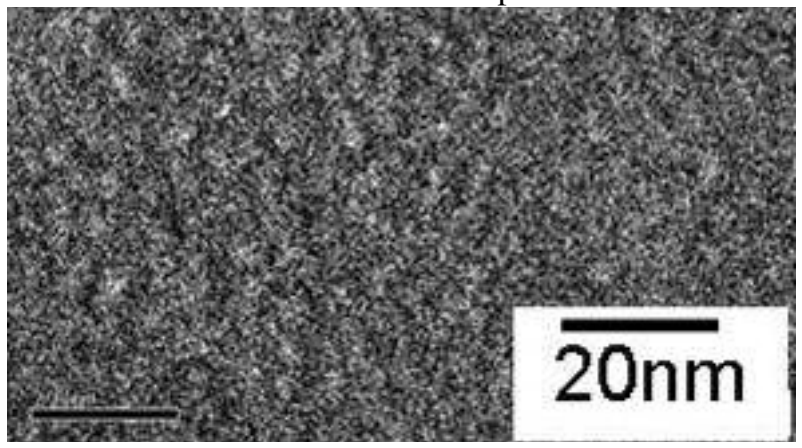

Ni element map

Figure 3: Energy filtered images of the as spun ribbon showing the presence of (Fe, $\mathrm{Ni})$-rich precipitates with a size of 2-4 nm.

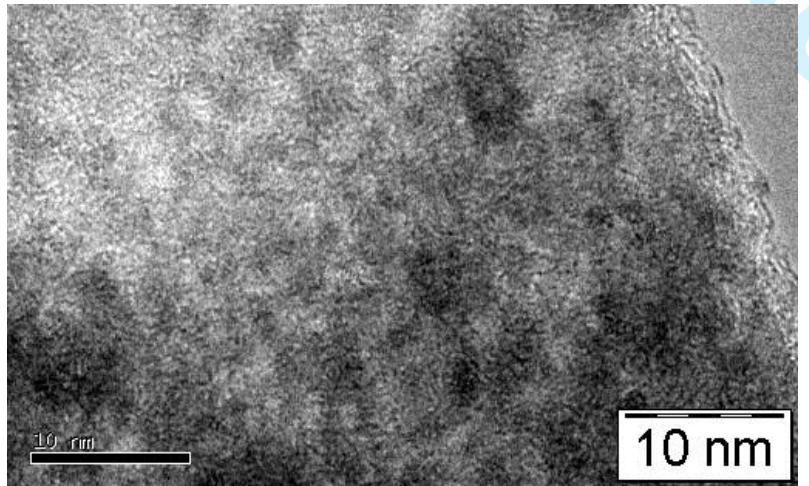

Zero loss image

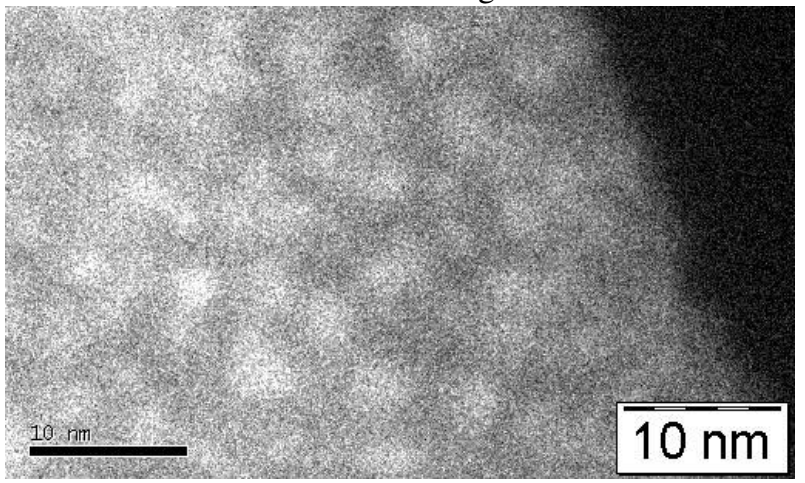

Fe element map

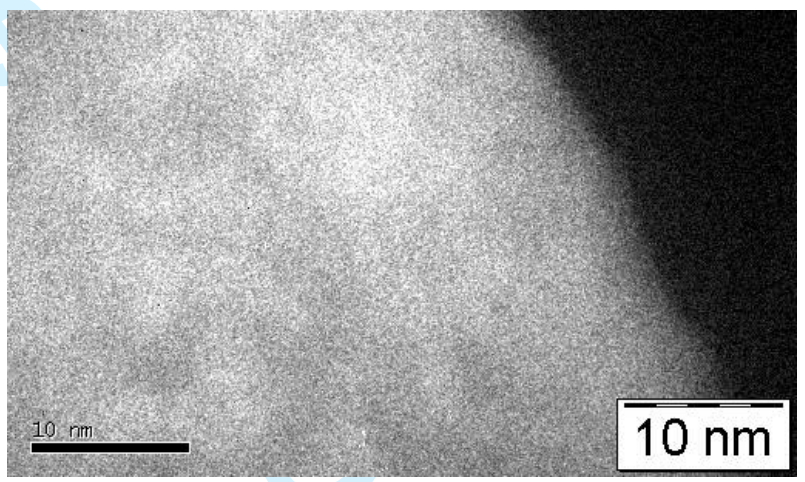

$\mathrm{Cu}$ element map

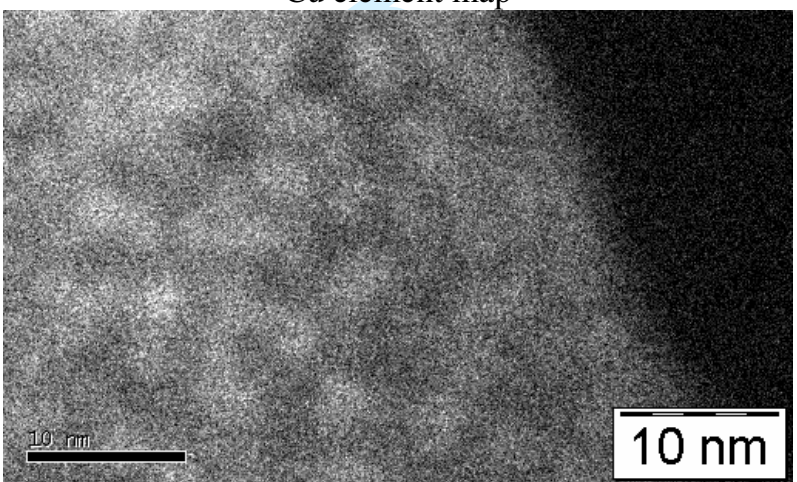

Ni element map

Figure 4: Energy filtered images of the sample annealed at $400^{\circ} \mathrm{C}$ for 2 hours. 


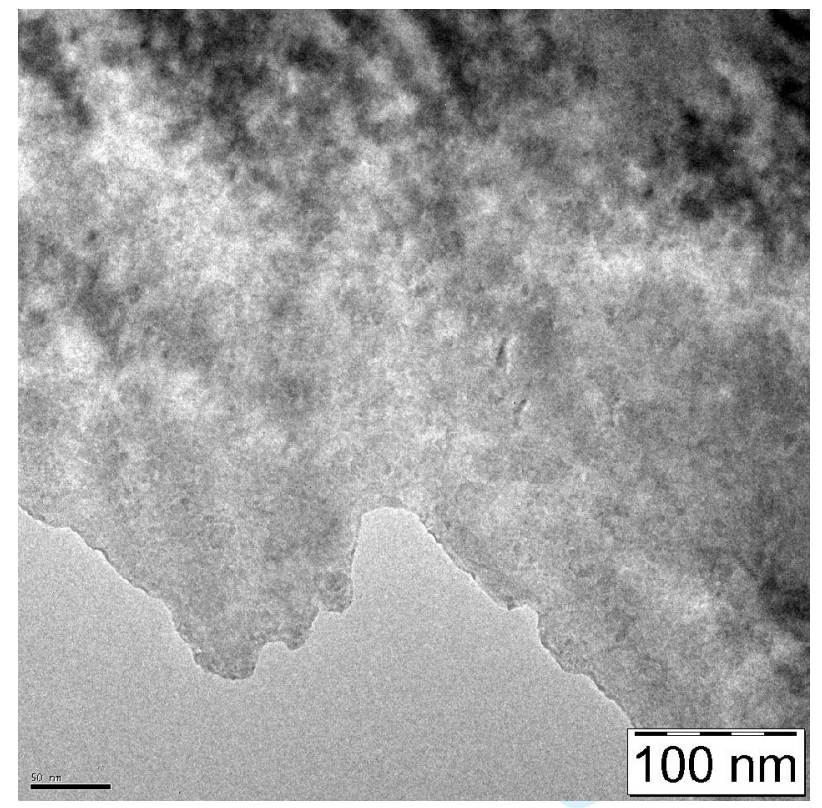

Zero loss image

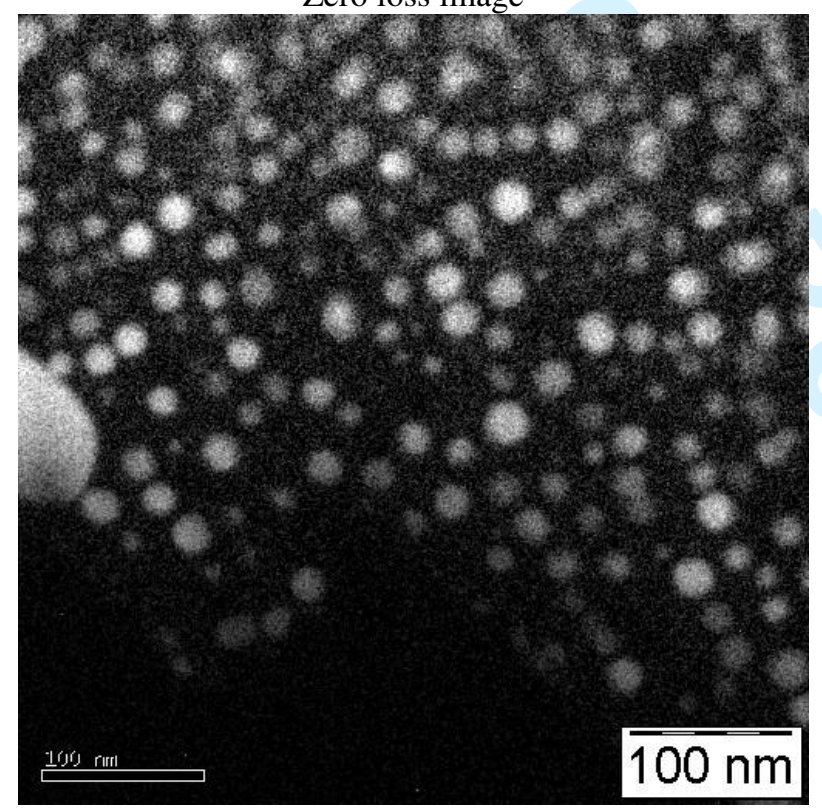

Fe element map

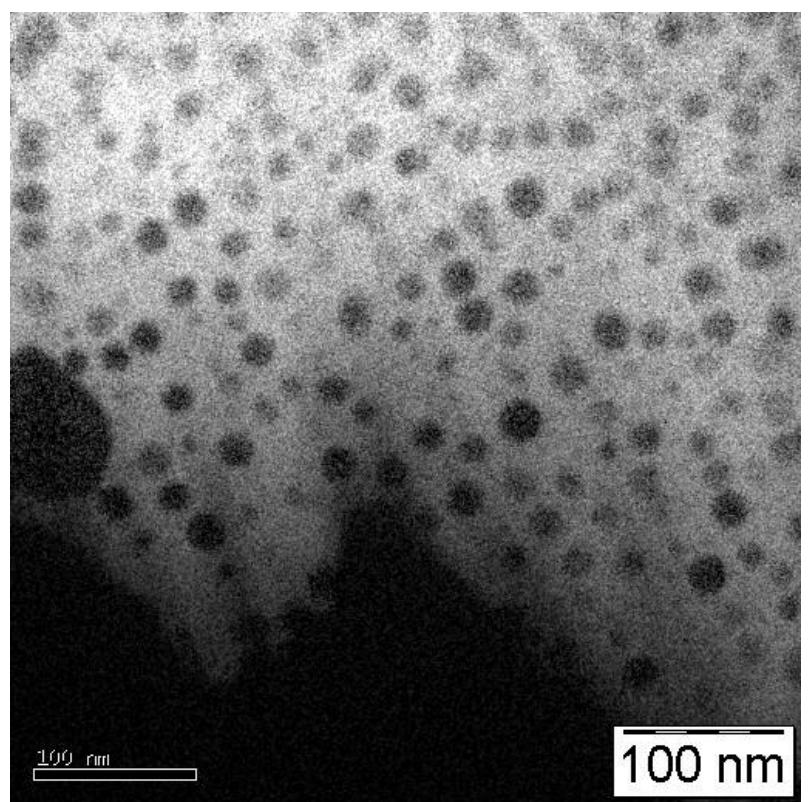

$\mathrm{Cu}$ element map

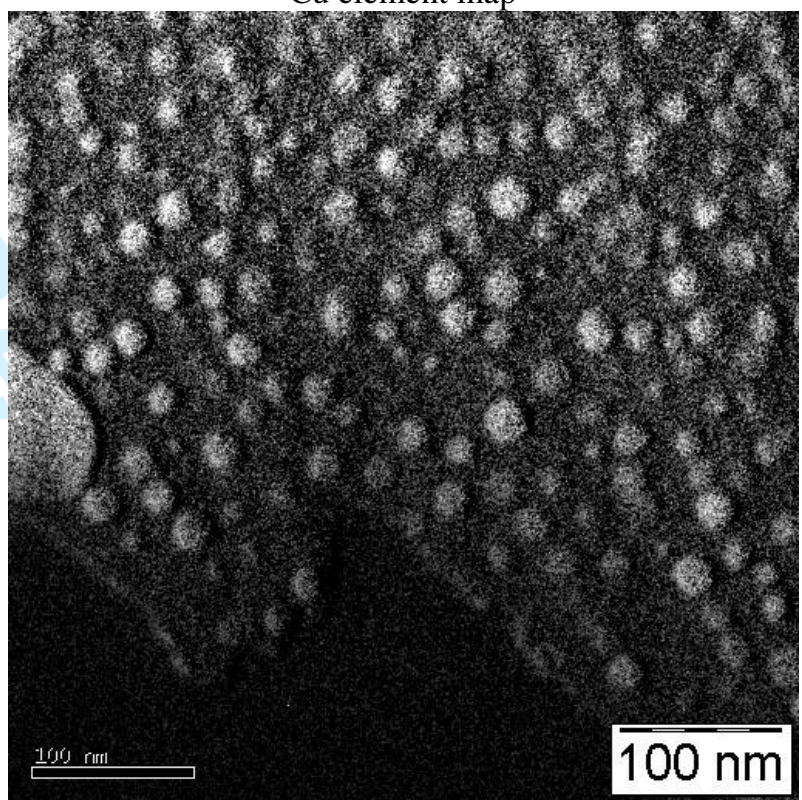

Ni element map

Figure 5: Energy filtered images of the sample annealed at $600^{\circ} \mathrm{C}$ for 24 hours. 


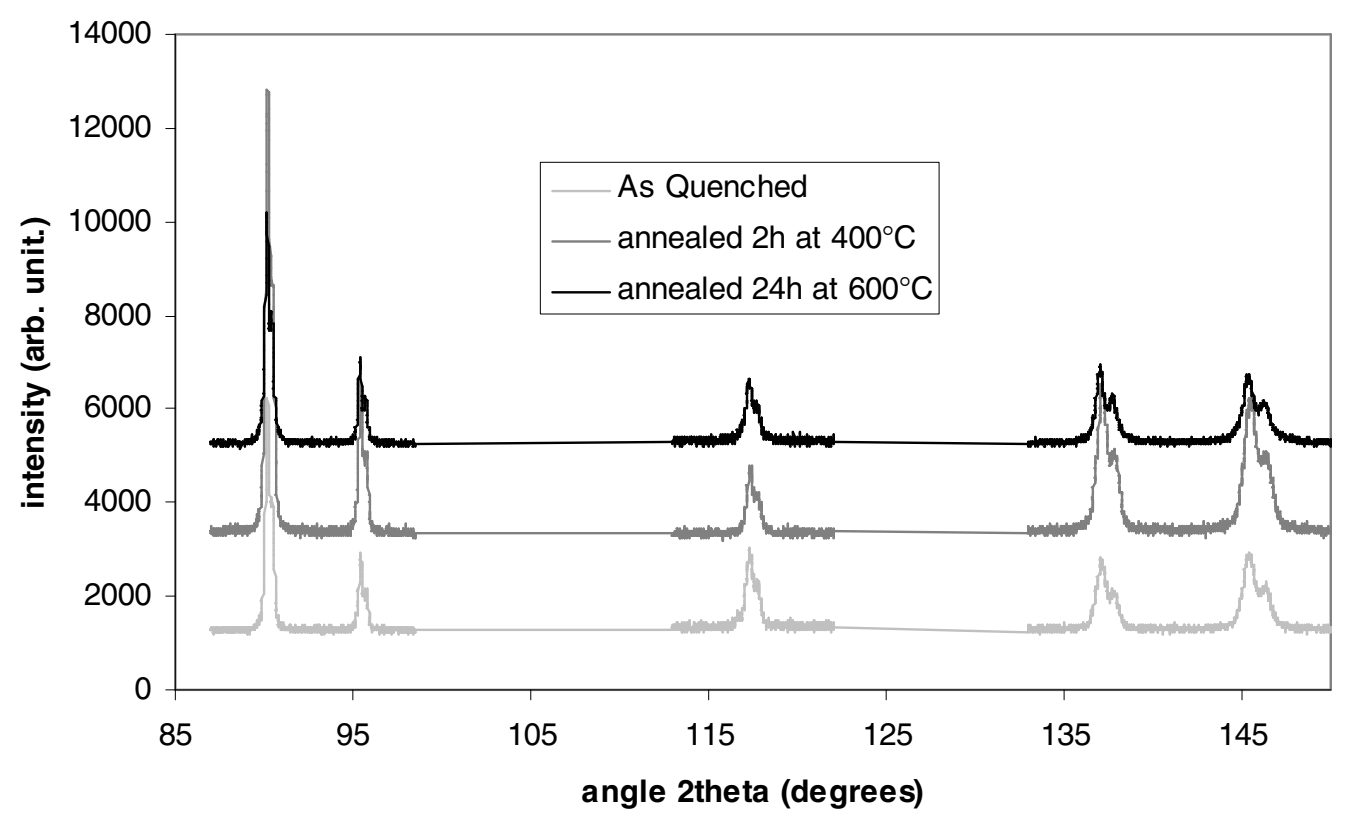

Figure 6: XRD pattern of the as spun and annealed samples.

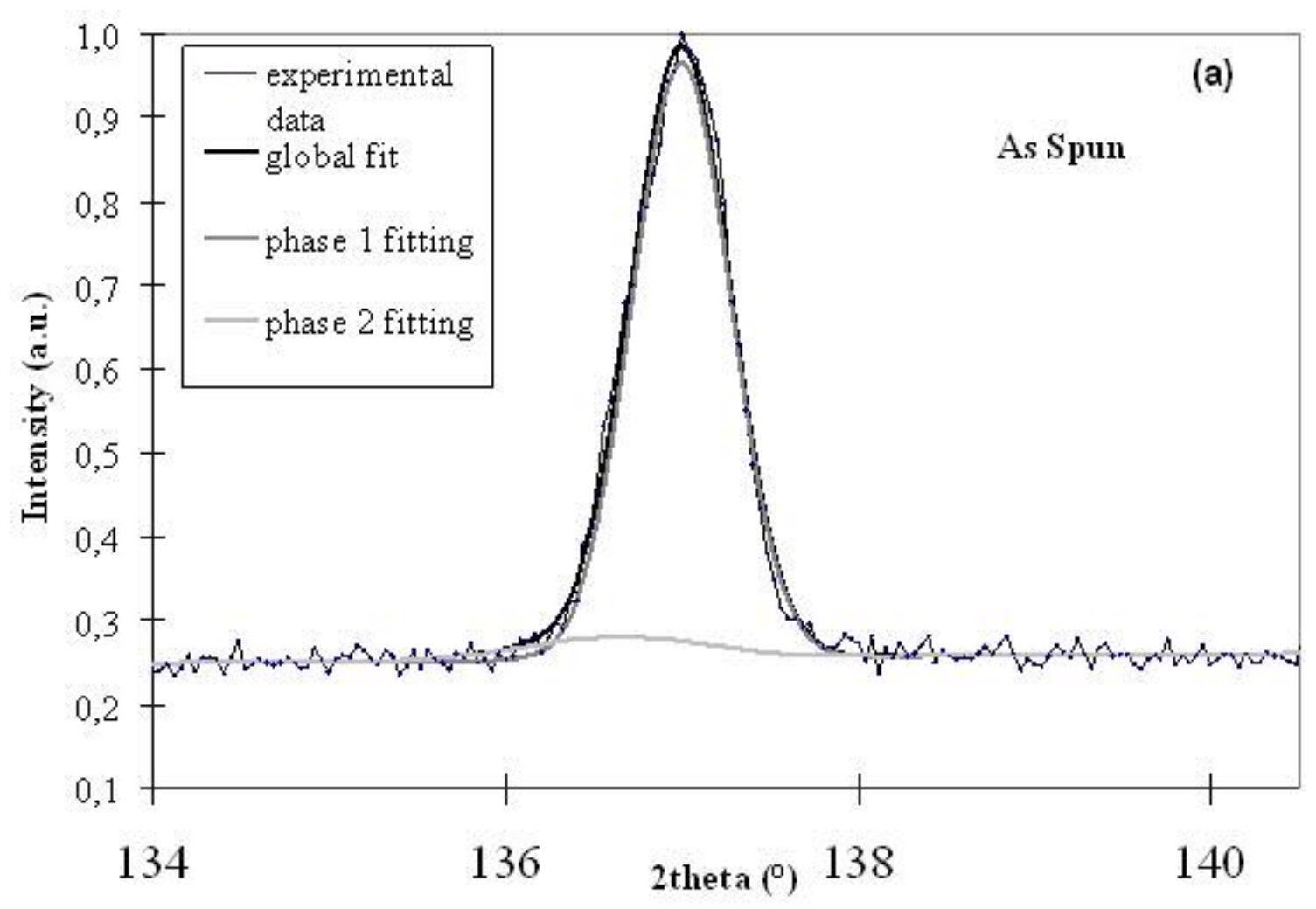




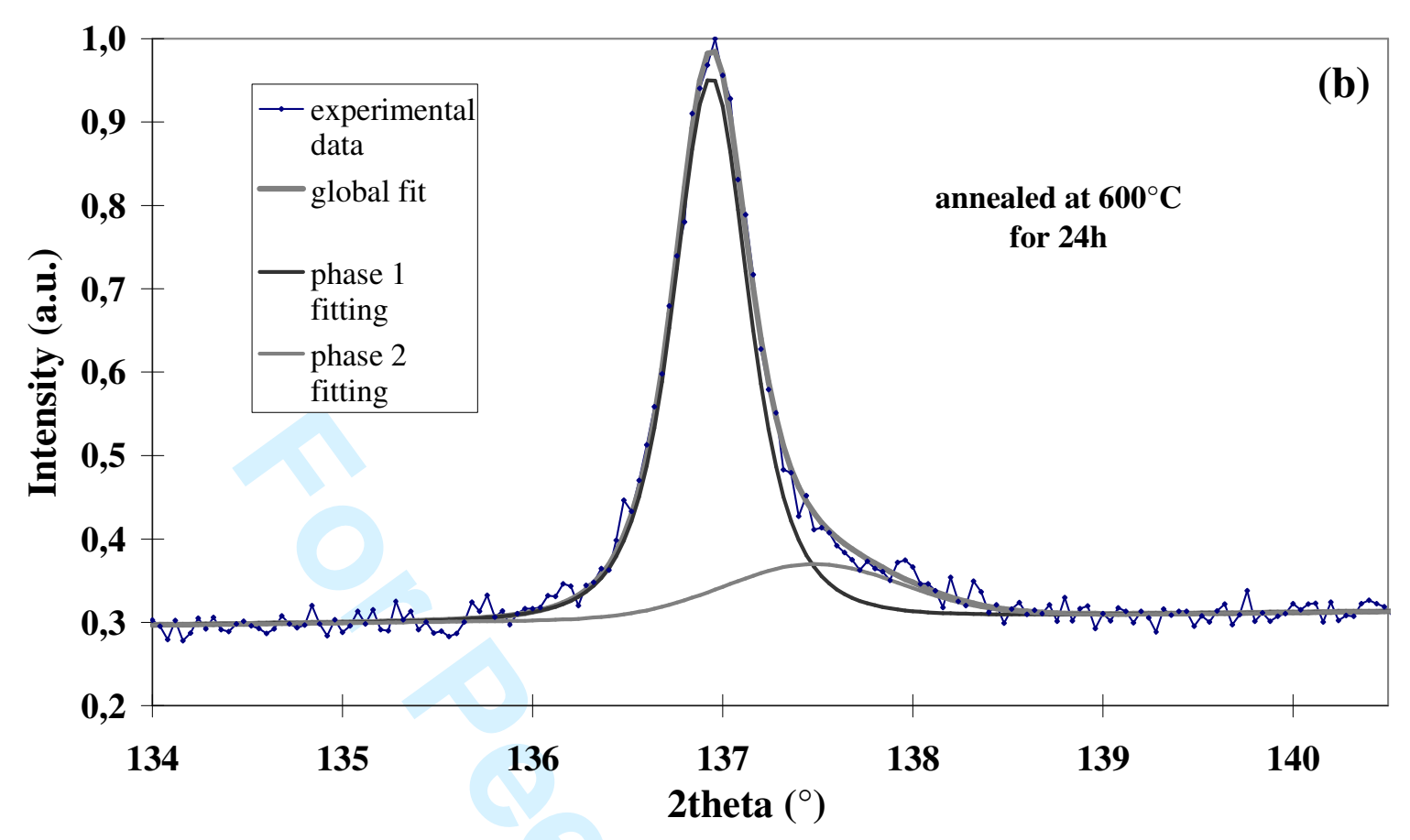

Figure 7: Example of phase extraction of the $\mathrm{Cu} 331$ peak for the as-spun sample (a) and the sample annealed at $600^{\circ} \mathrm{C}$ for $24 \mathrm{~h}(\mathrm{~b})$, showing the presence of two phases in the ribbon. The phase 1 is the $\mathrm{Cu}$ rich phase, and the phase 2 is the $(\mathrm{Fe}, \mathrm{Ni})$-rich phase

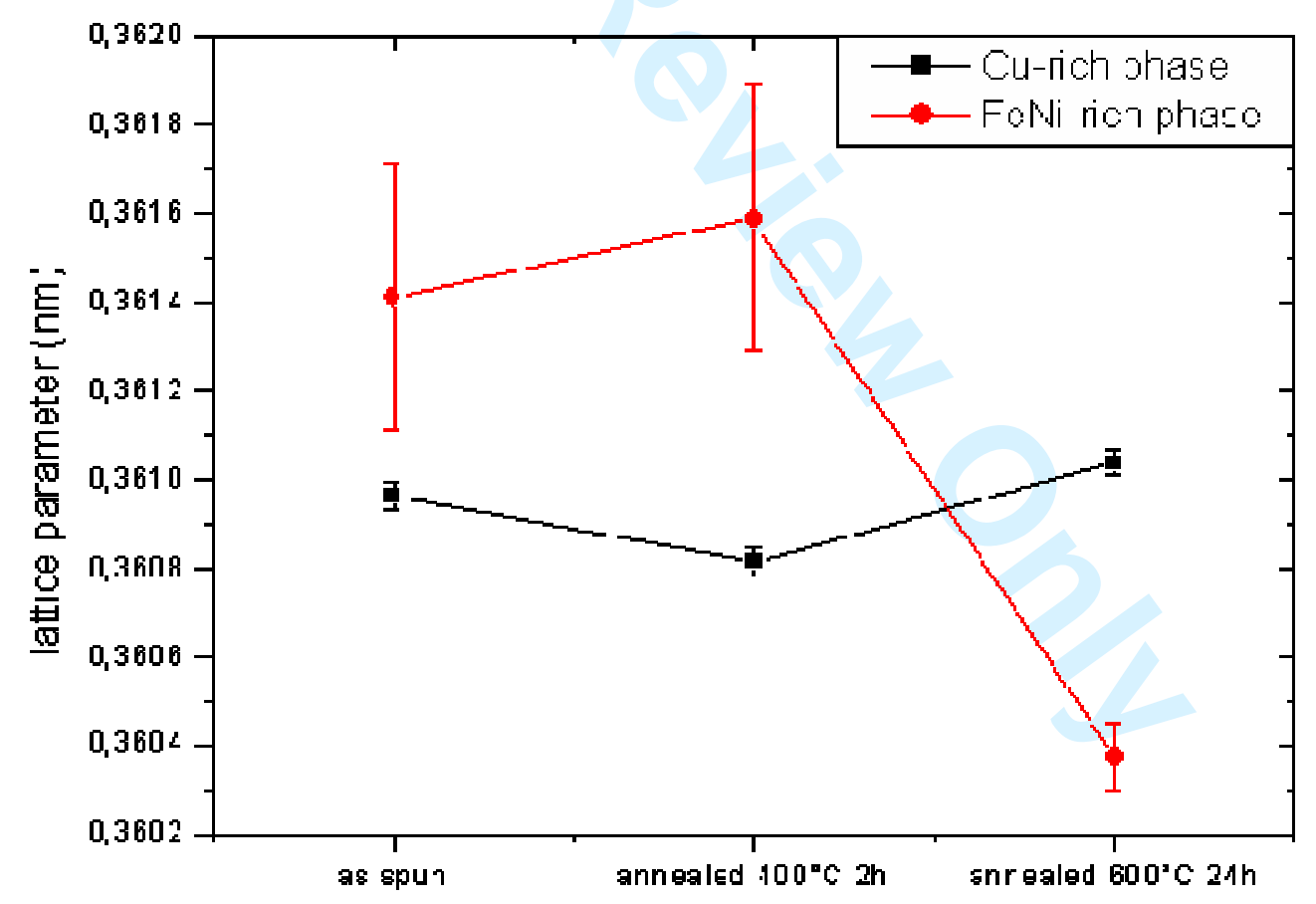

Figure 8: Evolution of the lattice parameter of the $\mathrm{Cu}$-rich phase and (Fe,Ni)-rich phase 